\title{
A Study on the Internet Information Management under the Background of Social Management Innovation \\ - A Case Study of the Comprehensive Portal
}

\author{
Xiaoming Qiao \\ Journal Editorial Department, Yunnan Normal University, Kunming City, \\ Yunnan Province, 650092, China
}

\begin{abstract}
Internet is not only a challenge to social management, but also an important field and a new tool for social management. The large-scale comprehensive portal and its social media are typical, whose management should learn from the concept of social management innovation with a variety of inter-sectional subjects. First of all, this paper analyzed the relationship between the Internet and social management, and then proposed new ideas of the Internet information management based on the above analysis.

Keywords: Comprehensive portal; Management subject; Social management; Internet
\end{abstract}

\section{Introduction}

As a representative of China's large-scale Websites, the traffic and influence of the comprehensive portal is far ahead of other sites in China, and it has long been among the mainstream media. Many interactive applications in the comprehensive portal carry the network behavior and information of the virtual society[1]. Therefore, its management method is more complicated than the news agency websites which can copy the traditional media supervision model, and its information management method has reference significance for the management of all content in the virtual society. This paper takes Tencent, Sina, Sohu, Netease 
and other comprehensive portals as examples to illustrate the management way of Internet information under the background of social management innovation from the perspective of the individual management of representative websites.

\section{The Relationship between the Internet and Social Management}

\subsection{The Internet poses a challenge to social management}

Internet information dissemination has characteristics of strong interactivity, fast spread speed and great influence. For example, the news comment system of comprehensive portals is the most developed and they pay more and more attention to the news comment system. Some illegal criminal activities are more rampant on the Internet. In particular, the comprehensive portal has gradually become an open platform and its derivatives become more popular, such as QQ, forums, blogs, podcasts, microblog and WeChat, which contributes to the dissemination of junk and bad information (such as pornography, violence, infringement, fraud and false advertising)[2]. These phenomena contain a certain social risk and pose new challenges to social management.

\subsection{The Internet is an important field of social management}

The Internet also affects the social management object, which is mainly that the social management functions extend to the virtual society. The boundary between the virtual society generated by the Internet and the real society is becoming more and more ambiguous. More and more social risks are generated by the virtual society, so that social management needs to manage the virtual society and the real society as a whole. The huge flow of several large comprehensive portal companies has determined that their status as China's largest information dissemination platform can not be shaken and they have greater impact on the community[3]. The bad information mixed in them has negative impact. Now the comprehensive portal has changed from a simple network entry to all forms of media which it leads to gradually. Therefore, the comprehensive portal is a representative with complex media forms and a variety of interactive technology, and its derivatives have a complex information interactive model, so that it is necessary to manage the information orderly.

\subsection{The Internet is a new tool for social management}

The Internet is a bridge of the direct communication between the government and the public and it is an important force to influence the public opinion field of mainstream media and the public. On one hand, the news sources of the Internet are mostly from national mainstream media, which represent the theme; on the other hand, online interactive speech occupies more and more space and the speech standpoints and ideas are more diverse, which forms a complex cultural 
context and reconstructs the ideology. For example, social media in comprehensive portals, especially the blog, microblog and WeChat, make the website a place where the collision between the ideology and opinions is the most intense, which reflects the dynamic process of exchanges, collision, confrontation or integration of the two public opinion fields. Social management is committed to solving social conflicts and online media will become a new tool for varieties of subjects to conduct social management. Information that the government make public can be published through news, microblog and other media in the network and they can monitor the trend of public opinion and ideology to understand the contradictions and things that the masses are concerned about, so that they can find budding and tendentious problems and take timely measures to resolve social conflicts.

\section{New Ideas of the Internet Information Management}

\subsection{In the national level: to focus on legislation and stress ways to guide public opinion}

First, we should pay attention to legal means and system measures. The prerequisite to strengthen the management of the network is to formulate a sound Internet legal system. The government should formulate specific laws for the Internet, improve the legislative level, define the legislative subject and penalties, and modify and supplement existing laws and regulations. The issuance and implementation subjects of China's Internet laws and regulations are independent departments, which results in the classification legislation. Besides, most of these laws and regulations are policy-based. These regulations do not clearly define many crimes on the Internet, which leads to the lack of norms and practicality. Therefore, the legal norms should have accurate and specific definition of cybercrime, and legalize online pornography and violence[4].

Second, the government should stress ways to guide public opinion. The guidance of public opinion is related to the national long-term stability, and national cohesion and centripetal force. The government should prevent excessive restrictions on the network public opinion, but also should resolutely fight criminal information On the Internet; it is necessary to promote the rich and various content and safeguard the orderly dissemination of information on the Internet. However, it is difficult to manege it in an appropriate way. For information with malicious attacks, slander, distortion of facts, rumors that threats to social stability, the government should strengthen control, and establish and improve the reporting mechanism to encourage Internet users to report bad information, so as to purify the ecological environment of the Internet.

3.2 In the company level: to pay less attention to commercialization and build a platform for public communication

First, the company should reduce the commercial content. Because of the fierce 
market competition, big companies are also facing some crises, especially the purely commercial comprehensive portals, whose revenues rely on themselves. Commerciality is the basis for the survival and development of websites. Although the website must have commercial profitability measures, they can avoid the more commercial content. The manifestation of commercial content is following: the hype that draws the eye, vulgar and false advertising and bad information that is made to retain users. From the perspective of the profitability and content of the comprehensive portal, the commercialized content does not actually bring much profit and traffic. On the contrary, content with less commercialization to a certain degree is not contradictory to the pursuit of profit. Content with less commercialization can enhance website credibility, shape the mainstream media brand and enhance user stickiness[5]. Therefore, comprehensive portals should improve the overall quality of the site editor and pay attention to the purification of information, so that the site content is suitable for people of all ages and it will promote healthy and orderly development of the information environment of the website.

Second, the company should promote the gradual downward shift in content production rights. Comprehensive portals should reduce the weird news, juicy tidbits and novelty news in important position of the page to provide more space for the user production content (UGC). The website needs to improve the editorial review mechanism and select valuable information from user production content to recommend it. They should pay special attention to content with positive energy, such as the public's struggle experience, positive life and touching news. Besides, the website should be concerned about representative and typical life or problems of different groups. In addition, the company ought to create a public exchange platform, which is to smooth channels of public opinion to stimulate the vitality of the user production content. Several comprehensive portals have been delegating the right of content production, such as blog and microblog. They are the supplement to news content and highlight the comments and opinions of cyber citizens and users.

\subsection{In the user level: to improve network literacy and actively supervise and report the website}

First, users should enhance self-management awareness. China's network society has been quite large, but many people do not have self-management awareness. Internet users need to improve the network media literacy, and conduct selfrestraint, self-protection and self-discipline. They can accumulate specialized knowledge, and cultivate independent thinking ability to make a clear distinction between right and wrong. Besides, they should not believe or cater to online information blindly. In addition, they should understand the rights and obligations of their act, master the bottom line of self-expression and bear the corresponding responsibility for their own network behavior[6].

Second, they should strengthen mutual supervision. The supervision of Internet users is a democratic supervision way which represents wishes of the cyber citizens and it is also a heteronomy in self-discipline. Its feasibility and 
effectiveness are greater than self-discipline. In addition to the need for external mechanisms to encourage and inspire Internet users' enthusiasm to monitor others, self-discipline supervision needs the responsibility and initiative of Internet users as a supporting role. Internet users should be familiar with how to participate in the management of websites, microblog and other social media. Besides, they should strengthen unity to supervise public opinion, report bad phenomena and stop rumors to build an organized, rational and orderly network society[7].

\section{Conclusion}

Whether from the development trend of the comprehensive portal management or from its development characteristics and needs, the downside of the website management has become the direction of the optimization of Internet information management model which changes the management way from the government telecommunications regulation to the governance with many subjects. This helps to stimulate the management vitality of many subjects. Besides, we should increase industry self-regulation and public supervision in the management model. In particular, we need to change users' passive management to active management.

However, in the current situation, the legislation at the national level is not perfect and ways to guide public opinion are not mature; the applicability of the corporate self-regulatory mechanism is poor and the implementation is weak, so that it is difficult to eliminate the impact of commercialization; the public has little enthusiasm to participate in the activity and cyber citizens lack self-quality, so we cannot expect that they have initiative of self-discipline and heteronomy in a short term; besides, the weakness of social force and social organization development leads to the limited participation of Internet users in the management. In general, the joint management system with a variety of forces has not been formed.

Therefore, we cannot blindly copy the concept of the Western governance and cannot advance the downside of the Internet management blindly. China's national conditions determine that the evolution of the Internet management model is still in the early stage and it is immature, so that we can only learn from the governance model to some degree and cannot immediately implement the governance model with the minimum state intervention, social control system and self-organizing network. We should take the management of Sina, Tencent and other major comprehensive portals as the breakthrough and continue to improve the legal, administrative and other rigid measures. Besides, the government is bound to include the self-regulatory mechanism of the company and the public into the framework of the national Internet information management mechanism, so as to form a new, orderly and harmonious situation of the Internet information management step by step. 


\section{References}

[1] Li Chunyu. A Study on the Travel Management Innovation under the Background of the "Internet +". Tourism Overview (On the Second Half of the Month), (12), pp.44-46, 2016.

[2] Zhang Weiqi. A Study on the Financial Management Innovation Ways under the Background of the Internet. Accounting Learning, (22), pp.58-60, 2016.

[3] Li Xuhong. A Research of the Tax Management Innovation under the Background of the "Internet +". Taxation Research, (11), pp.121-124, 2016.

[4] Yin Yuanyuan. A Research of the Government Administration Innovation under the Background of the Internet. Drama Home, (07), pp.246, 2016.

[5] Mao Huayang, Liu Jiali. A Study on the Financial Management Innovation Ways under the Background of the "Internet+". Finance and Accounting for International Commerce, (01), pp.44-45, 2016.

[6] Li Yiling. A Study on the Communist Youth League Work in Colleges under the Background of Social Management Innovation. Studies in Ideological Education, (11), pp.91-94, 2012.

[7] Zhu Kun. A Thinking on the Social Management Innovation in the Internet era. Journal of Chifeng University (Natural Science Edition), (16), pp.18-19, 2012. 